\title{
PRODUÇÃO CARTOGRÁFICA PARA ELABORAÇÃO DE INVENTÁRIO FÍSICO-TERRITORIAL DE BACIA HIDROGRÁFICA NO PONTAL DO PARANAPANEMA
}

\section{CARTOGRAPHIC PRODUCTION FOR PHYSICAL AND TERRITORIAL INVENTORY OF WATERSHED IN THE PONTAL DO PARANAPANEMA}

\author{
Bruno Magro Rodrigues, Lucas Prado Osco, Ana Paula Marques Ramos \\ ${ }^{1}$ Universidade do Oeste Paulista, Mestrado em Meio Ambiente e Desenvolvimento \\ Regional, Membro do Núcleo de Estudos Ambientais e Geoprocessamento \\ (NEAGEO), Presidente Prudente - SP. E-mail: b magro@hotmail.com
}

RESUMO - O presente trabalho objetiva realizar a produção cartográfica que compõe o inventário físico-territorial de uma subbacia hidrográfica da Unidade de Gerenciamento de Recursos Hídricos do Pontal do Paranapanema (UGRHI-22). A área de estudo consiste no médio curso da bacia do rio Pirapozinho, Estado de São Paulo. Fez-se a elaboração dos seguintes mapas temáticos: declividade, hipsometria, pedologia, unidades geológicas aflorantes, unidades morfológicas, subsistema climático, uso e cobertura da terra, fisionomias da vegetação, suscetibilidade a erosão e mapa de distribuição da drenagem. Os mapas foram gerados pelo processo de compilação de dados. Os resultados possibilitam compreender atributos físicos do médio curso da bacia do rio Pirapozinho, os quais auxiliam na interpretação da dinâmica ambiental da bacia. Conclui-se que a produção cartográfica contribui para a elaboração do inventário físico territorial da bacia e, consequente, planejamento ambiental da mesma.

Palavras-chave: Planejamento Ambiental; Mapas Temáticos; Inventário Físico-Territorial; Bacia Hidrográfica.

ABSTRACT - This study aims to develop the cartographic production that composes the physical-territorial inventory of a sub-watershed of the Unit of Pontal do Paranapanema Water Resources Management (UGRHI-22). The study area consists of the middle reaches of the watershed river Pirapozinho, State of São Paulo. It was produced the following thematic maps: slope, hypsometry, pedology, exposed geological units, morphological units, climatic subsystem, use and land cover, vegetation, physiognomy, erosion susceptibility and drainage distribution. These maps were designed using data compilation process. Results allow understanding physical attributes of the middle

Recebido em: 19/08/2015 Revisado em: 28/08/2015 Aprovado em: 09/09/2015 reaches of the watershed river Pirapozinho, which aid in the interpretation of the environmental dynamics of the watershed. We conclude that cartographic production contributes to the development of territorial physical inventory of the basin and, consequently, for the 
environmental planning of it.

Keywords: Environmental Planning; Thematic Maps; Physical and Territorial Inventory; Watershed. 


\section{INTRODUÇÃO}

O planejamento ambiental de uma bacia hidrográfica se constitui em um importante instrumento para 0 gerenciamento de seus recursos hídricos (MOTA, 2003; LEAL, 2012). O planejamento ambiental pode ser considerado um instrumento de suporte ao processo de tomada de decisões que visa adequar as ações e intervenções de diferentes agentes, tais como governamentais, econômicos e sociais, aos sistemas naturais (SANTOS, 2004). A função do planejamento ambiental é contribuir para a manutenção das condições ecológicas, por meio do uso racional e da proteção dos recursos do meio ambiente, para o desenvolvimento eficiente e eficaz das atividades antrópicas (MOTA, 2003; RODRIGUEZ; SILVA; CAVALCANTI, 2013). Segundo Mota (2003), as medidas de proteção da vegetação, de otimização do uso e ocupação do solo, de controle da erosão têm reflexos na conservação dos recursos hídricos de uma bacia hidrográfica, tanto de modo qualitativo quanto quantitativo.

De acordo com Rodriguez, Silva e Cavalcanti (2013), o planejamento ambiental pode ser realizado a partir de uma análise integrada da paisagem. Tais autores explicam que essa análise integrada consiste em um conjunto de métodos aplicados para caracterizar e interpretar a estrutura da paisagem, bem como estudar suas propriedades, a história do seu desenvolvimento, os processos de formação e transformação da mesma, como sistemas manejáveis e administráveis. Nas proposições de Rodrigues (1994), Leal (1995) e Rodrigues et al. (2013), a concepção metodológica de planejamento ambiental, a partir da análise integrada da paisagem, constitui-se em várias etapas, cada uma caracterizada por seus componentes e produtos específicos, também por instrumentos concretos da análise regional e da geoecologia. As principais etapas que constituem o planejamento ambiental de uma bacia hidrográfica são: inventário físico-territorial, diagnóstico ambiental, prognóstico e proposições de melhorias do estado ambiental da bacia hidrográfica em estudo (RODRIGUEZ, 1994; LEAL, 1995; RODRIGUEZ; SILVA; CAVALCANTI, 2013).

Segundo Leal (1995), o inventário físico-territorial constitui-se na base para todo o processo de planejamento ambiental, pois consiste no levantamento detalhado das informações gerais da bacia hidrográfica de interesse, isto é, o inventário é caracterizado como uma etapa de compreensão da realidade que se pretende estudar. Para tanto, o inventário deve ser entendido como um processo contínuo de avaliação, pois em sua elaboração pode-se encontrar dificuldades, seja para a obtenção de 
informações sobre a área de estudo ou mesmo por dificuldades técnicas relacionadas à etapa de produção cartográfica que caracteriza a área de interesse (LEAL, 1995).

Esse contexto evidencia a importância da Cartografia, enquanto ciência e técnica, para suporte à atividade de planejamento ambiental e de gerenciamento dos recursos hídricos de uma bacia hidrográfica, por exemplo, ao que se refere à etapa de elaboração do inventário físico-territorial da área estudada. Os produtos cartográficos, tais como mapas e cartas temáticas, possuem fundamental importância para o suporte às análises ambientais. Isso porque, a partir de tais produtos, pode-se descrever os fatores e elementos que auxiliam na compreensão do estado ambiental da região de estudo, como, por exemplo, uma bacia hidrográfica. Sendo assim, a produção cartográfica, tal como a que compõe um inventário físico-territorial visando o planejamento ambiental, auxilia na análise das características naturais de uma bacia hidrográfica, relacionando-as entre si, bem como com as atividades antrópicas e seus impactos no meio físico.

O objetivo desse trabalho é realizar a produção cartográfica que irá compor o inventário físico-territorial de uma sub-bacia hidrográfica do Pontal do Paranapanema, Estado de São Paulo. O objeto de estudo refere-se ao médio curso da bacia hidrográfica do rio Pirapozinho. As questões que este trabalho respondem são 'Quais elementos integram um inventário físicoterritorial?' e 'Qual a característica físicoterritorial da área que compõe o médio curso da bacia hidrográfica do rio Pirapozinho?'. A principal contribuição desse trabalho é auxiliar na caracterização física da região do médio curso da bacia do rio Pirapozinho, para a qual é de suma relevância quando da atividade de planejamento ambiental de uma bacia hidrográfica. Cabe ressaltar que o presente trabalho está inserido em um contexto de projeto maior, o qual vem sendo desenvolvido com apoio da CAPES (Coordenação de Aperfeiçoamento de Pessoal do Nível Superior), no Mestrado em Meio Ambiente e Desenvolvimento Regional (MMADRE) da UNOESTE (Universidade do Oeste Paulista).

\section{METODOLOGIA}

A produção cartográfica para a elaboração do inventário físico-territorial do médio curso da bacia hidrográfica do rio Pirapozinho foi dividido em duas etapas: caracterização da área de estudo e organização dos dados para a preparação dos mapas temáticos que compõem um inventário físico-territorial. 


\section{Área de estudo}

O médio curso da bacia hidrográfica do rio Pirapozinho possui uma área aproximada de $459 \mathrm{~km}^{2}$ e está inserido na 22a Unidade de Gerenciamento de Recursos Hídricos do Pontal do Paranapanema (UGRHI22). Localizado no extremo oeste do estado de São Paulo, as coordenadas do ponto central da bacia são Latitude $22^{\circ} 17^{\prime} 48^{\prime \prime} \mathrm{S}$ e Longitude $51^{\circ} 43^{\prime}$ 09"O. Na Figura 1 é apresentada a localização do médio curso da bacia do rio Pirapozinho na URGHI-22 e no contexto do Estado de São Paulo. A área de estudo possui comportamento singular, diferente do que normalmente se encontra na região da bacia hidrográfica do Pontal do Paranapanema. Uma vasta parcela da bacia hidrográfica do rio Pirapozinho situa-se na região conhecida como Depressão de Presidente Bernardes (PAULA; SILVA, 2003), ou Planalto das Lagoas (STEIN, 1999), caracterizada por seu relevo plano, pouco dissecado, com padrões de drenagem dendrítico e, ao centro, semi-circular, com a presença de lagoas sobre os setores de menor declividade.

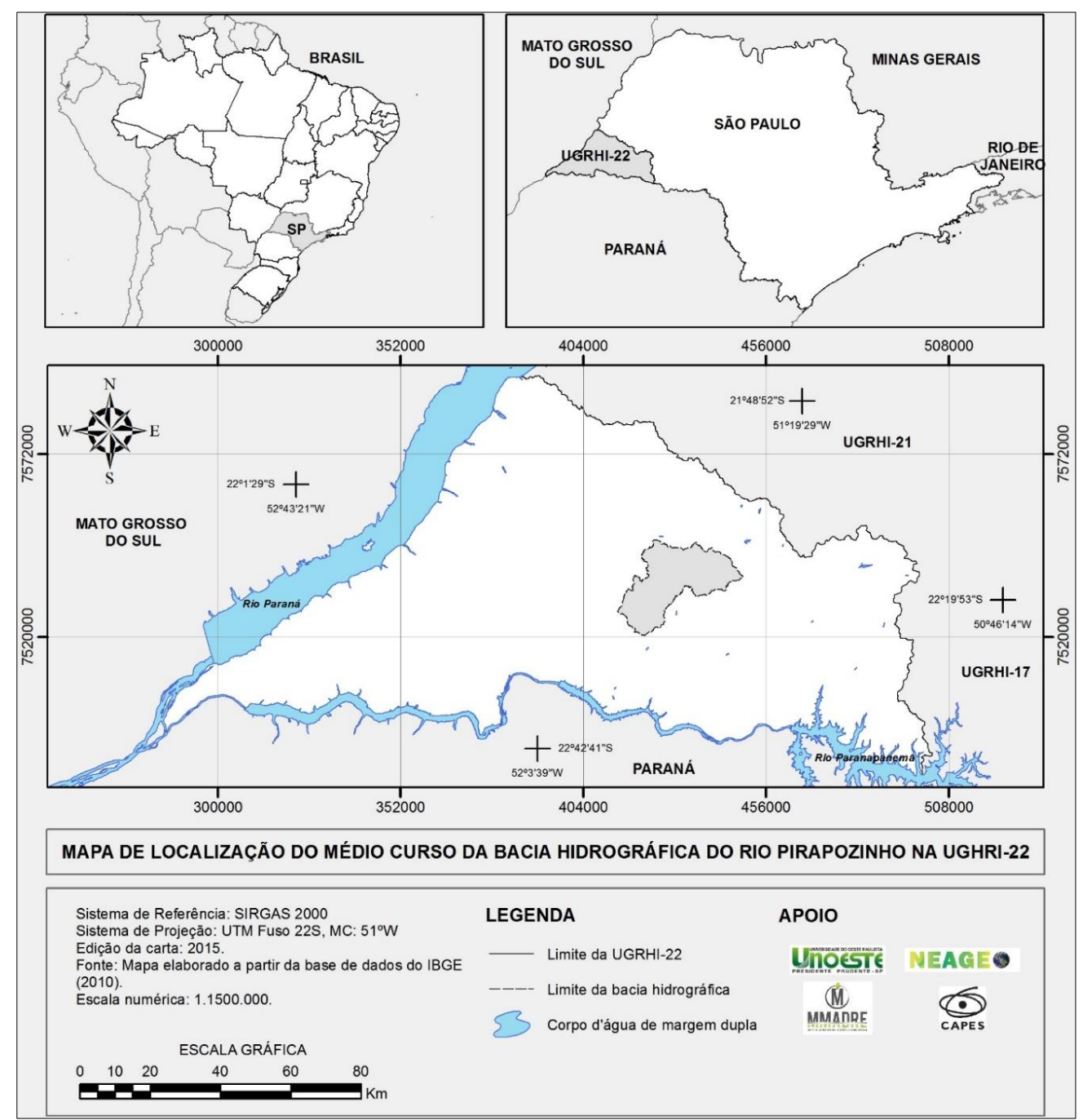

Figura 1. Localização do médio curso da bacia do rio Pirapozinho. 
A Depressão de Presidente Bernardes é um amplo setor de terreno suavizado com solos mais espessos do que 0 de normalmente encontrado na região, de caráter latossólico conforme apontado no mapeamento de Embrapa (1999). Alguns indícios interpretados na paisagem remetem a possibilidade de atividades tectônicas atuantes até o presente momento, bem como de processos morfogênicos decorrentes do tempo, que são responsáveis pela singularidade da região (STEIN; PONÇANO; SAAD, 2003).

\section{Elaboração dos Mapas Temáticos para a} Composição do Inventário Físico-territorial

Os mapas temáticos foram compilados a partir de dados disponíveis gratuitamente em diferentes instituições de pesquisa e ensino no Brasil, e foram elaborados conforme o recorte do limite do médio curso da bacia hidrográfica do rio Pirapozinho. Todos os produtos foram gerados no software da empresa ESRI, o ArcGIS 10. Para compor o inventário físicoterritorial, fez-se a elaboração dos seguintes mapas temáticos: declividade, hipsometria, pedologia, unidades geológicas aflorantes, unidades morfológicas, subsistema climático, uso e cobertura da terra, fisionomias da vegetação, suscetibilidade a erosão e distribuição da drenagem.
O mapa de declividade, representado na escala 1:200.000, foi elaborado a partir da compilação dos dados da imagem de radar SRTM (Shuttle Radar Topography Mission) disponibilizados para a região, no ano de 2014, com resolução espacial de 30 metros. Definiu-se as seguintes classes de declividade: 0-5 \% até declividade de $20 \%$ ou mais. As classes de declividade foram divididas da seguinte maneira: Até 5\%; maior que $5 \%$; até $10 \%$; maior que $10 \%$, até $15 \%$; maior que $15 \%$, até $20 \%$; e maior que $20 \%$. Quanto ao mapa de hipsometria, este tem por função representar classes de diferentes altitudes. Tal representação ocorre por esquemas de cores variando do verde escuro para menores altitudes, amarelo e vermelho para altitudes medianas-altas, até a altitudes maiores representadas por branco. No mapa hipsométrico, as classes foram classificadas a partir de regiões de maior altitude para regiões de menor altitude, sendo divididas em 5 classes distintas.

Para o mapa pedológico na escala 1:200.000, utilizou-se os dados coletados pela Empresa Brasileira de Pesquisa Agropecuária (Embrapa), em 1999, e disponibilizados pela Cooperativa de Serviços e Pesquisas Tecnológicas e Industriais (1999). As informações foram extraídas para a área estudada. Este mapa será relevante para a identificação das características pedológicas 
da bacia, destacando-se classes texturais de cada tipologia de solo. Para elaborar o mapa de unidades geológicas, na escala 1:200.000, utilizou-se os dados do mapa geológico produzido por Almeida et al. (1981) e disponibilizado pela Cooperativa de Serviços e Pesquisas Tecnológicas (CPTI), em 1999, na escala 1:250.000. Este mapa auxilia na compreensão dos afloramentos das formações geológicas presentes na bacia, possibilitando realizar comparativos com as demais feições físicas existentes na bacia.

O mapa de unidades morfológicas foi compilado na escala 1:200.000, a partir do mapa geomorfológico disponibilizado pelo CPTI, em 1999, com a classificação do Instituto de Pesquisas Tecnológicas - IPT (1981). A partir do mapa de unidades morfológicas, pode-se compreender qual o tipo de relevo presente na bacia estudada, bem como suas classificações e localizações na área. Para elaborar o mapa de subsistema climático na escala 1:200.000, utilizou-se os dados levantados por Boin (2000) e apresentados no mapa de Unidades Climáticas. Buscou-se apresentar as demais unidades além da unidade em que a bacia se encontra inserida, uma vez que existe a necessidade de se demonstrar o contexto regional onde se encontra a área estudada.

O mapa de uso e cobertura da terra foi produzido utilizando imagens do satélite Landsat 8 na data de 18 de janeiro de 2015, destacando as seguintes classes: corpos d'água, mancha urbana, florestas arbóreas, silvicultura, pastagem, agricultura temporária, solo exposto. Encontram-se representadas, ainda, a hidrografia (rios de margem simples) e as estradas principais presentes na bacia. A hidrografia foi definida a partir de dados do Instituto Brasileiro de Geografia e Estatística (IBGE) e as estradas a partir das imagens Landsat 8. O mapa contendo as fisionomias da vegetação foi elaborado na escala 1:200.000, a partir da classificação supervisionada sobre imagem de satélite Landsat 7, sensor ETM+ do ano de 2013, tendo sua classificação baseada no mapa de biomas do IBGE. A partir desses dados, foram identificadas as fisionomias de vegetação presentes na bacia.

O mapa de suscetibilidade à erosão foi elaborado na escala 1:200.000, a partir dos dados do mapa de erodibilidade disponibilizados pela Cooperativa de Serviços e Pesquisas Tecnológicas (1999) na escala de 1:250.000. As classes abordadas correspondem aos seguintes níveis: médio, alto e muito alto. Os dados expostos servem de base para identificação de setores mais suscetíveis a processos erosivos. O mapa de drenagem foi elaborado na escala 1:200.000, a partir de dados da drenagem disponibilizados na base de dados do IBGE e de dados extraídos da imagem de radar SRTM, com resolução espacial de 30 metros. 
Esse mapa é relevante para auxiliar a compreensão a distribuição da rede de drenagem inserida no médio curso da bacia hidrográfica do rio Pirapozinho, além de proporcionar uma perspectiva do relevo a partir da imagem de radar.

\section{RESULTADOS}

O mapa temático de classes de declividade (Figura 2) revela que as maiores classes de declividade se encontram, principalmente, nas regiões com maior concentração de cabeceira de drenagem, localizadas na porção nordeste da área estudada, evidenciada por seu relevo bem dissecado. Destaca-se também um vasto trecho de baixa declividade na porção central da bacia, coincidindo com a região denominada de Depressão de Presidente Bernardes. Tais fatores observados na declividade remetem-se a influências no comportamento da dinâmica fluvial.

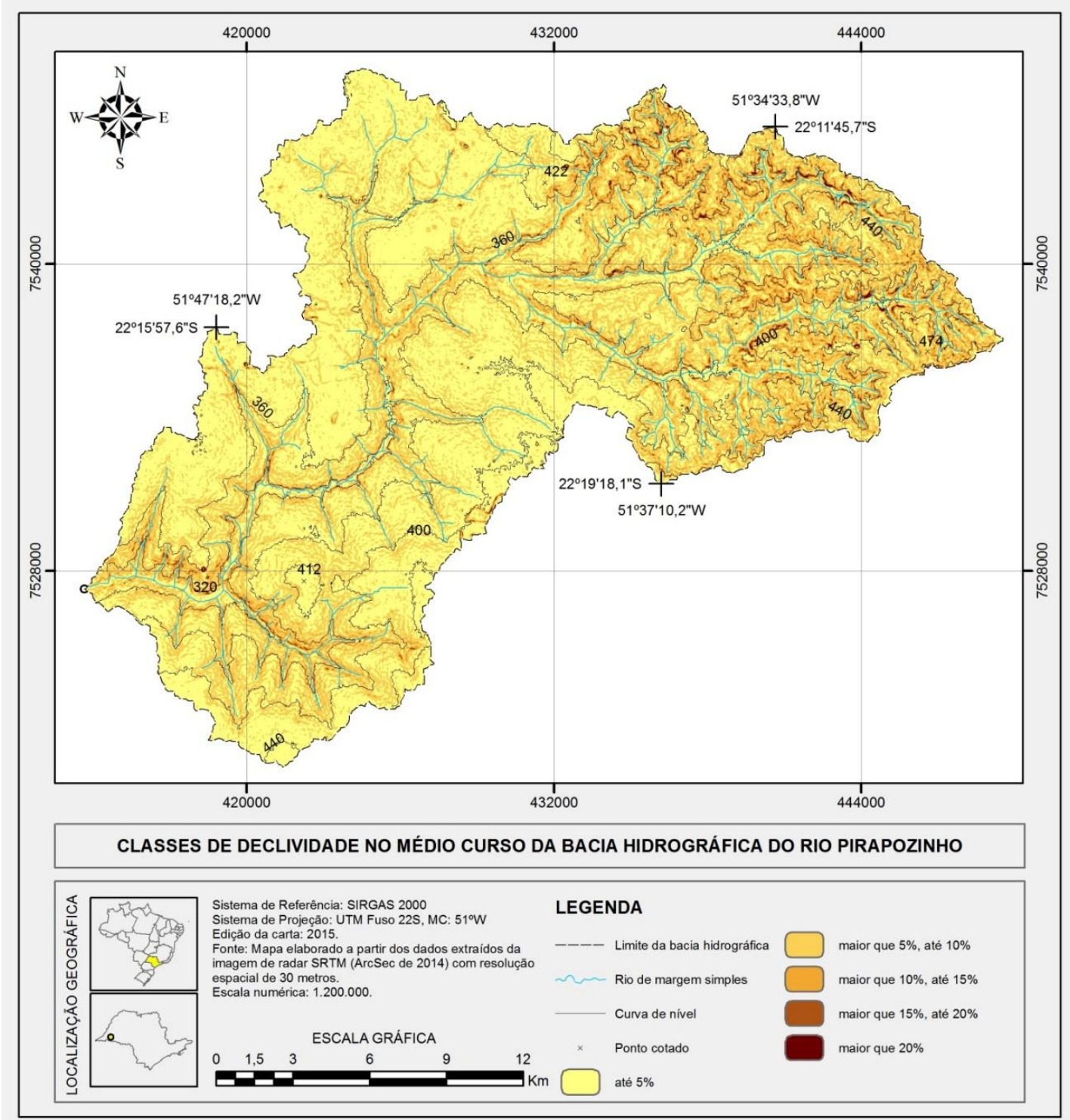

Figura 2. Classes de declividade no médio curso da bacia hidrográfica do rio Pirapozinho. 
A Figura 3 apresenta a hipsometria do médio curso da bacia do rio Pirapozinho. As áreas com altitudes classificadas como média para alta estão localizadas principalmente nos trechos a nordeste e norte e em algumas localidades ao sul e sudeste da bacia. As áreas com altitudes classificadas como média para média-baixa são encontradas na maior parte da bacia, mais uma vez coincidindo com as características da região. As menores altitudes estão na região centro-sul da bacia, acompanhando as proximidades dos cursos d'água das porções no centro-sul.

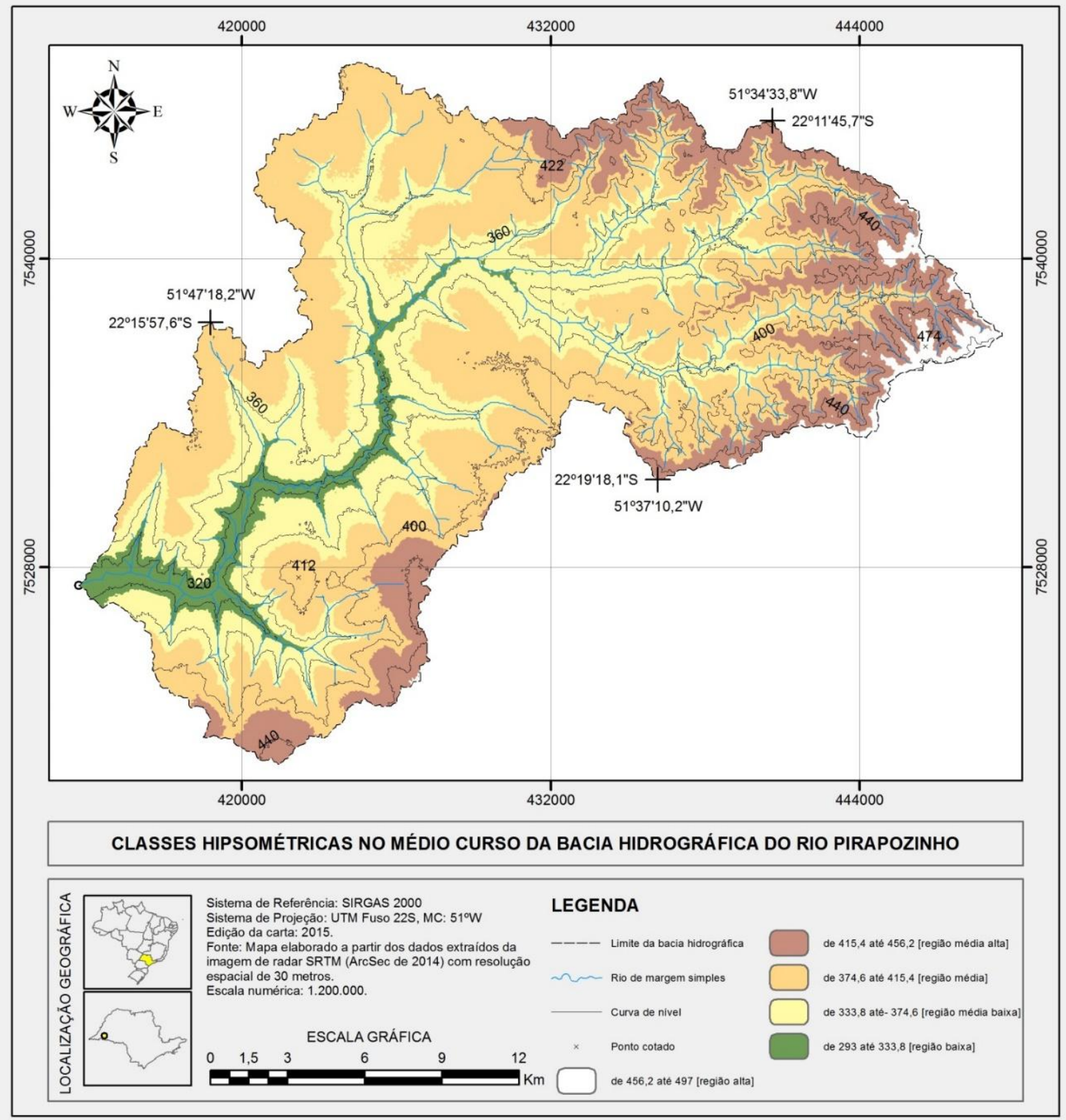

Figura 3. Mapa de classes hipsométricas no médio curso da bacia hidrográfica do rio Pirapozinho. 
A pedologia da bacia hidrográfica é representada a seguir na Figura 4, que corresponde ao mapa pedológico da área em questão. Nas regiões mais elevadas, localizadas na porção nordeste da bacia, destaca-se a presença de solos do tipo Argissolos. $\mathrm{Na}$ porção central há a predominância de Latossolos Vermelhos. Os solos presentes na porção nordeste são Argissolos Vermelho-Amarelo Eutrófico (PVA4 e PVA5) e possuem características muito similares. Ambos apresentam textura arenosa/média, são pertencentes a relevo ondulado e suave ondulado.
A região central (Figura 4) ainda possui Argissolo Vermelho Distrófico. Destaca-se na porção central, a presença dos Latossolos Vermelhos (LV29 e LV49), com características semelhantes. O LV29 é descrito como Latossolo Vermelho Distroférricos e Eutroférricos de textura argilosa. O LV49 corresponde ao Latossolo Vermelho Distróficos e relevo suave ondulado. Ainda há um pequeno ponto da bacia com a presença do Argissolo VermelhoAmarelo PVA2.

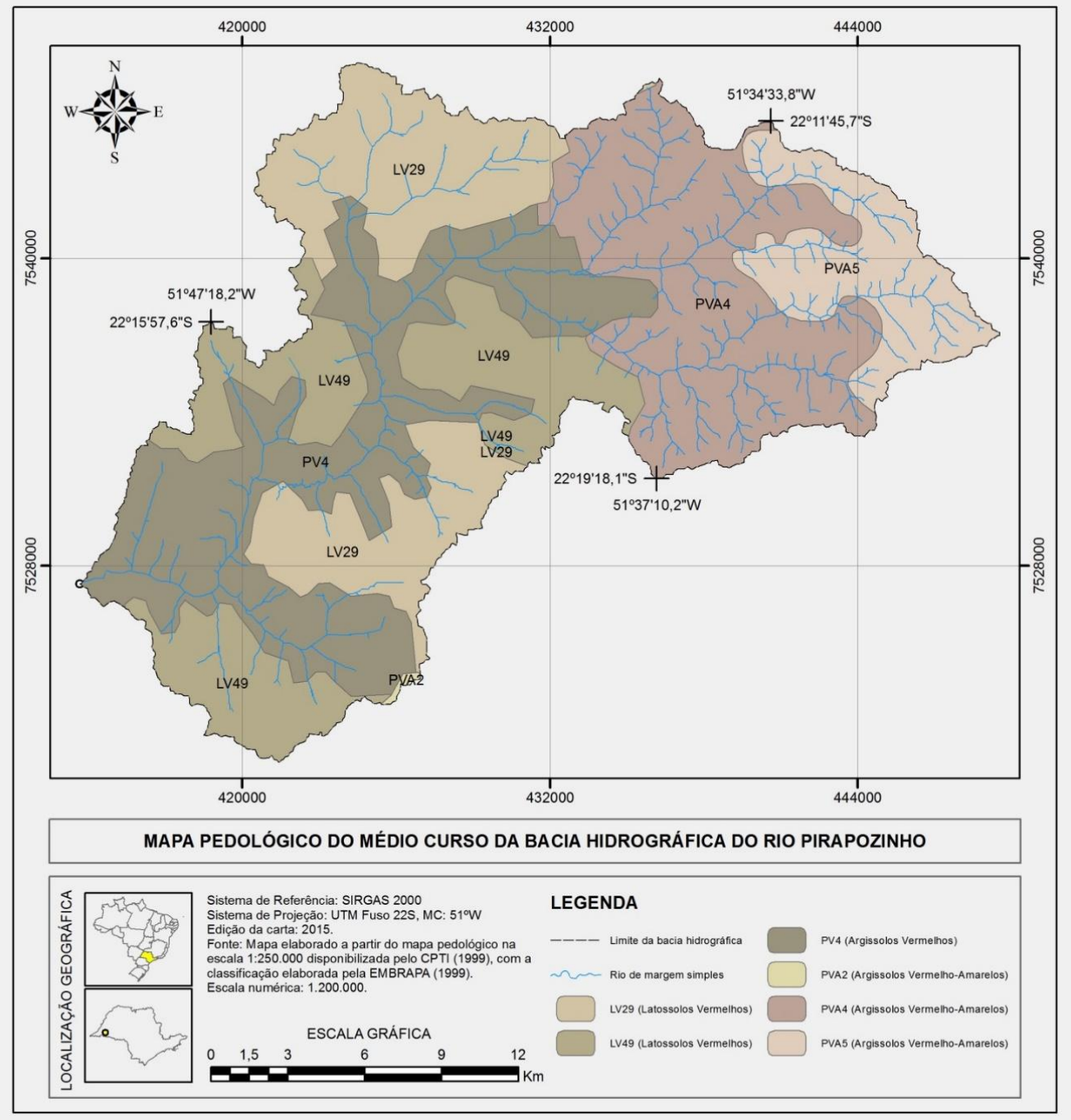

Figura 4. Mapa pedológico do médio curso da bacia hidrográfica do rio Pirapozinho 
A Figura 5 apresenta o mapa de unidades geológicas. Destaca-se neste mapa as divisões da formação Adamantina, presentes na bacia, subdivididas em unidades de mapeamento $\mathrm{Ka}_{\mathrm{l}}, \mathrm{Ka}_{\mathrm{Iv}}$ e $\mathrm{Ka} \mathrm{a}_{\mathrm{v}}$, onde $\mathrm{a}$ unidade $\mathrm{Ka}_{\text {l }}$ é predominante, coincidindo com a Depressão de Presidente Bernardes. As unidades $\mathrm{Ka}_{\mathrm{IV}}$ e Kav localizam-se na porção nordeste da bacia. Como características físicas, as unidades $\mathrm{Ka}_{\mathrm{iv}}$ e $\mathrm{Ka} \mathrm{a}_{\mathrm{v}}$ possuem particularidades próximas, apresentando a intercalação de bancos silto-argilosos com cimentação carbonática. Relaciona-se, ainda, os fatores supracitados com a geomorfologia da bacia estudada, visto que a geologia é considerada um fator interno de formação do relevo, enquanto os processos climáticos e biológicos atuam como fatores externos.

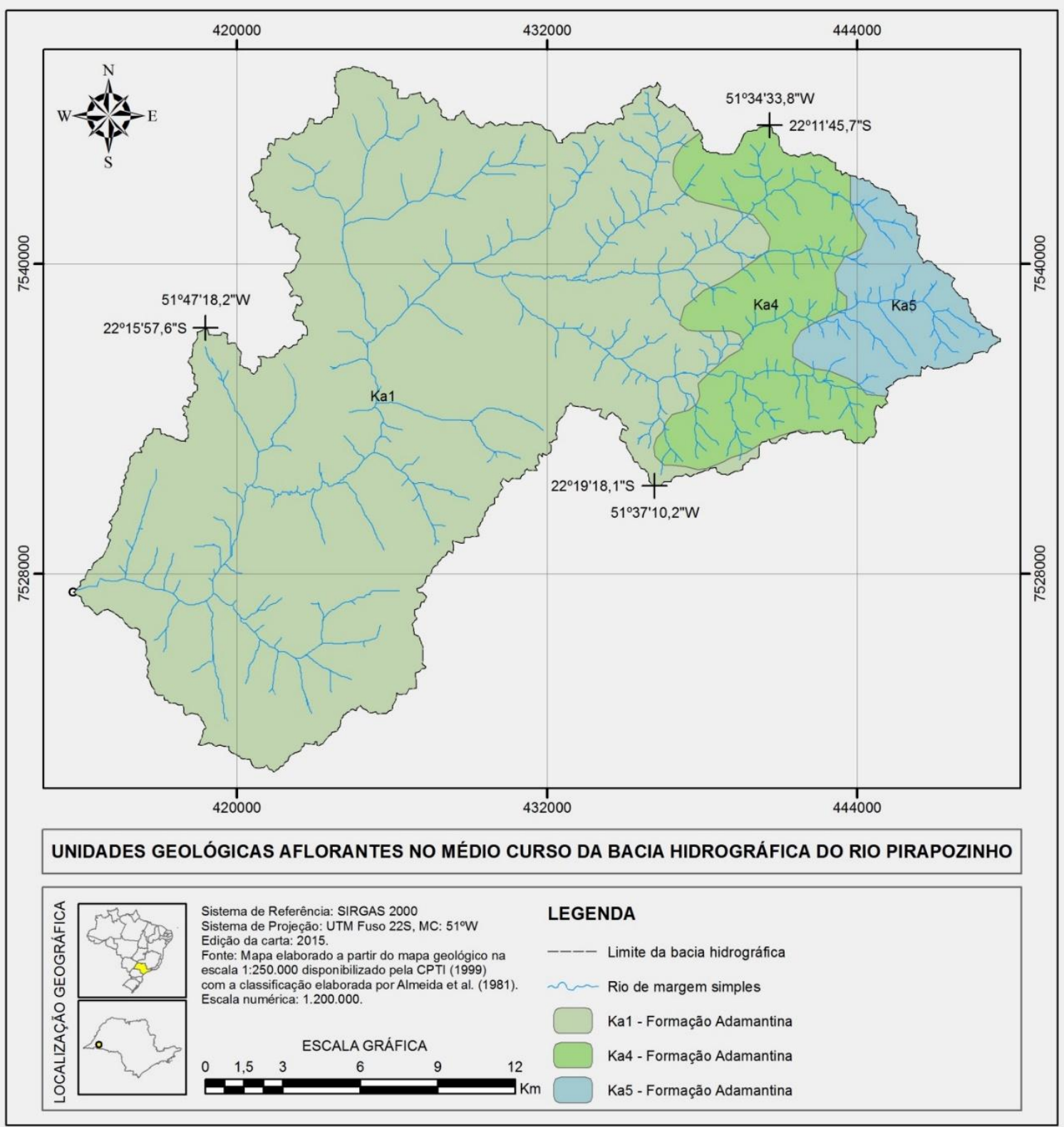

Figura 5. Unidades geológicas aflorantes no médio curso da bacia hidrográfica do rio Pirapozinho 
A Figura 6 corresponde ao mapa de unidades morfológicas e reforça essa relação dos elementos da natureza. A bacia possui duas divisões no relevo, sendo na porção nordeste e norte a predominância de Colinas Médias e nas porções centro sul e noroeste a predominância de Colinas Amplas. As regiões denominadas de Colinas Amplas compreendem áreas planas, com área superior a $4 \mathrm{~km}^{2}$, com relevo com topos extensos e aplainados, vertentes com perfis retilíneos a convexos. As Colinas Médias possuem o comportamento parecido com a região de Colinas Amplas, com predominância de interflúvios de 1 a $4 \mathrm{~km}^{2}$, topos aplainados e vertentes com perfis convexos a retilíneo (INSTITUTO DE PESQUISAS TECNOLÓGICAS DO ESTADO DE SÃO PAULO, 1981).

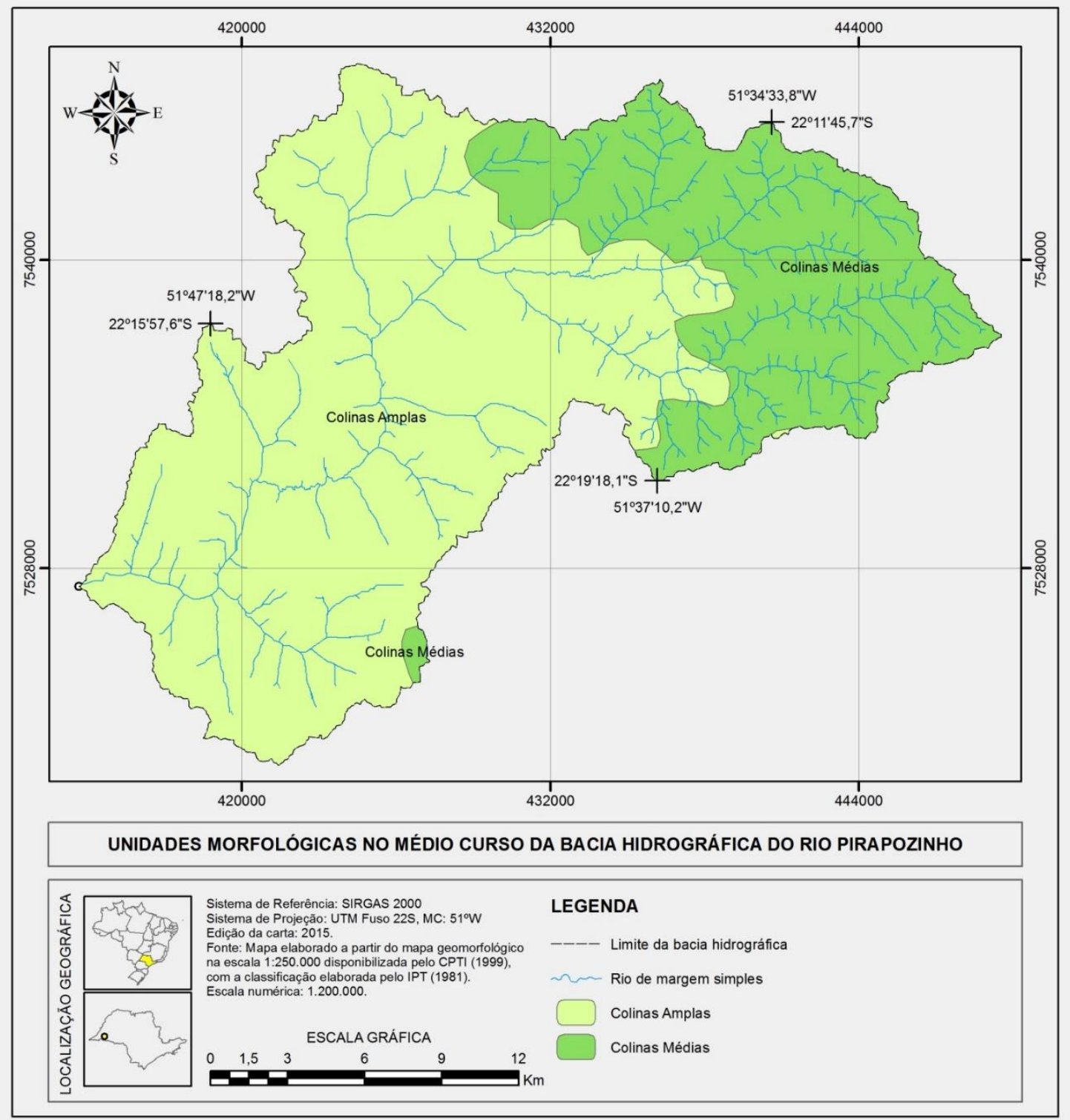

Figura 6. Unidades morfológicas no médio curso da bacia hidrográfica do rio Pirapozinho 
A Figura 7 destaca o subsistema climático da área estudada, conforme elaborado por Boin (2000). A área estudada está localizada em um único subsistema climático denominado BIVma, caracterizado por altitudes médias, pluviosidade média anual entre 1200 a $1300 \mathrm{~mm}$, com chuvas de origem principal frontal, com predominância de chuvas advectivas e poucas chuvas convectivas. A média de dias com chuva no ano compreende entre 80 a 100 dias.

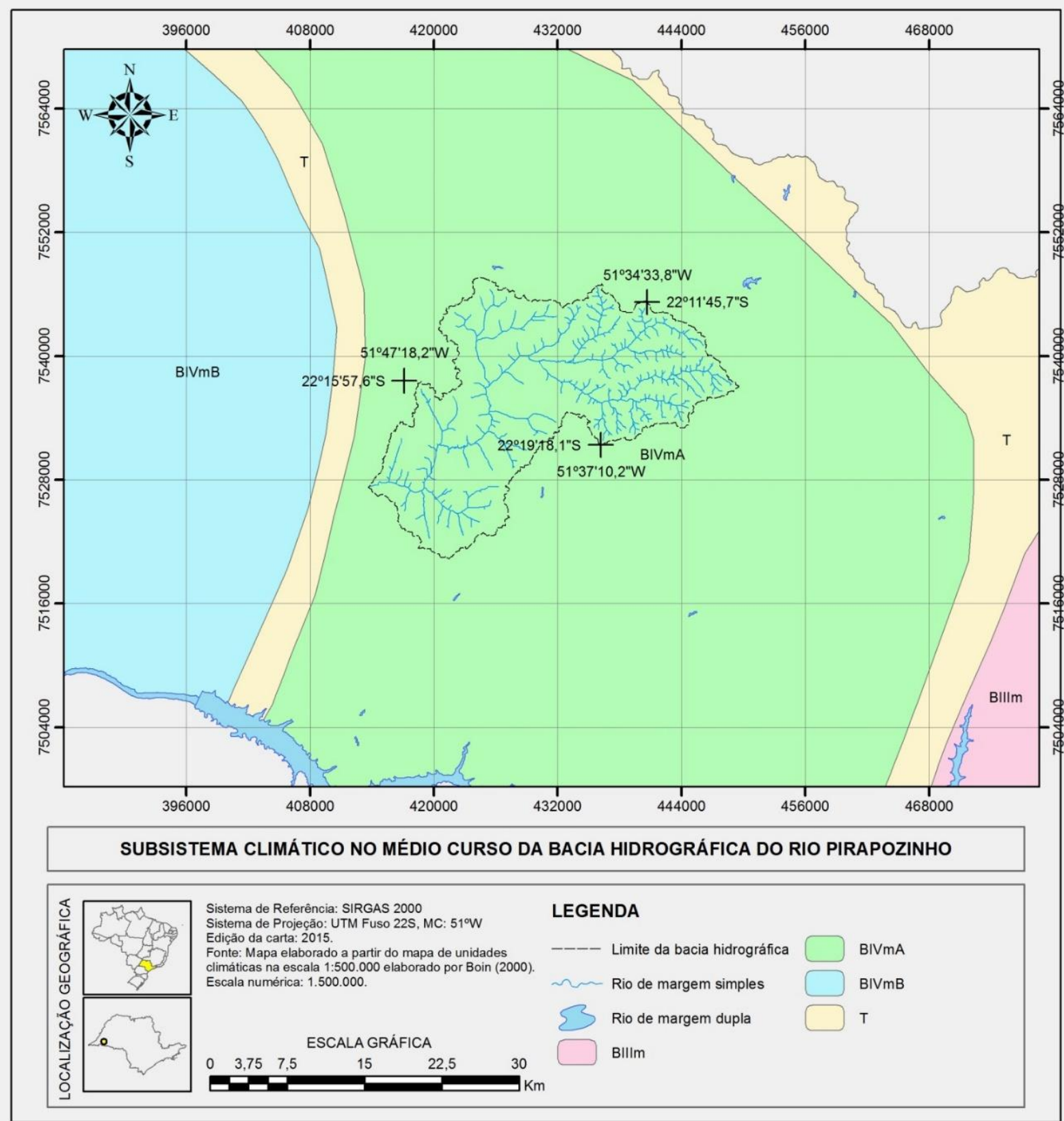

Figura 7. Subsistema climático no médio curso da bacia hidrográfica do rio Pirapozinho

A Figura 8 ilustra o uso e cobertura da terra na bacia durante o mês de janeiro do ano de 2015. Destaca-se uma grande incidência de agricultura temporária, principalmente a presença da cana-de-açúcar dentro desse setor. Há a evidência, também, 
da presença de pastagem em grande volume de área, expondo os solos a processos erosivos com maior facilidade, pois associamse às áreas desprovidas de vegetação. Trechos de região plana são ideais para o desenvolvimento de culturas como a canade-açúcar, visto a necessidade de utilização de maquinários para auxiliar os processos de produção, abrangendo períodos de plantio, aplicação de defensivos, colheita e revolvimento do solo. Essas características explicam a elevada incidência desta cultura na área em estudo, principalmente na região da Depressão de Presidente Bernardes. cobertura específica podendo-se consistir em solos em preparo para o plantio, solos posteriores a épocas de colheita e outros tipos de solos descobertos de uma forma geral. A bacia, ainda, apresenta áreas cobertas por vegetações de porte altivo que, mesmo em quantias deficientes, exercem sua função de proteção dos solos e dos recursos hídricos contra contaminações, movimentações de partículas e processos erosivos. O mapa destaca também a presença de áreas de silvicultura, onde é possível destacar o eucalipto e pinus como culturas características dessa atividade.

Os solos expostos (ou nú) são caracterizados por não apresentarem uma

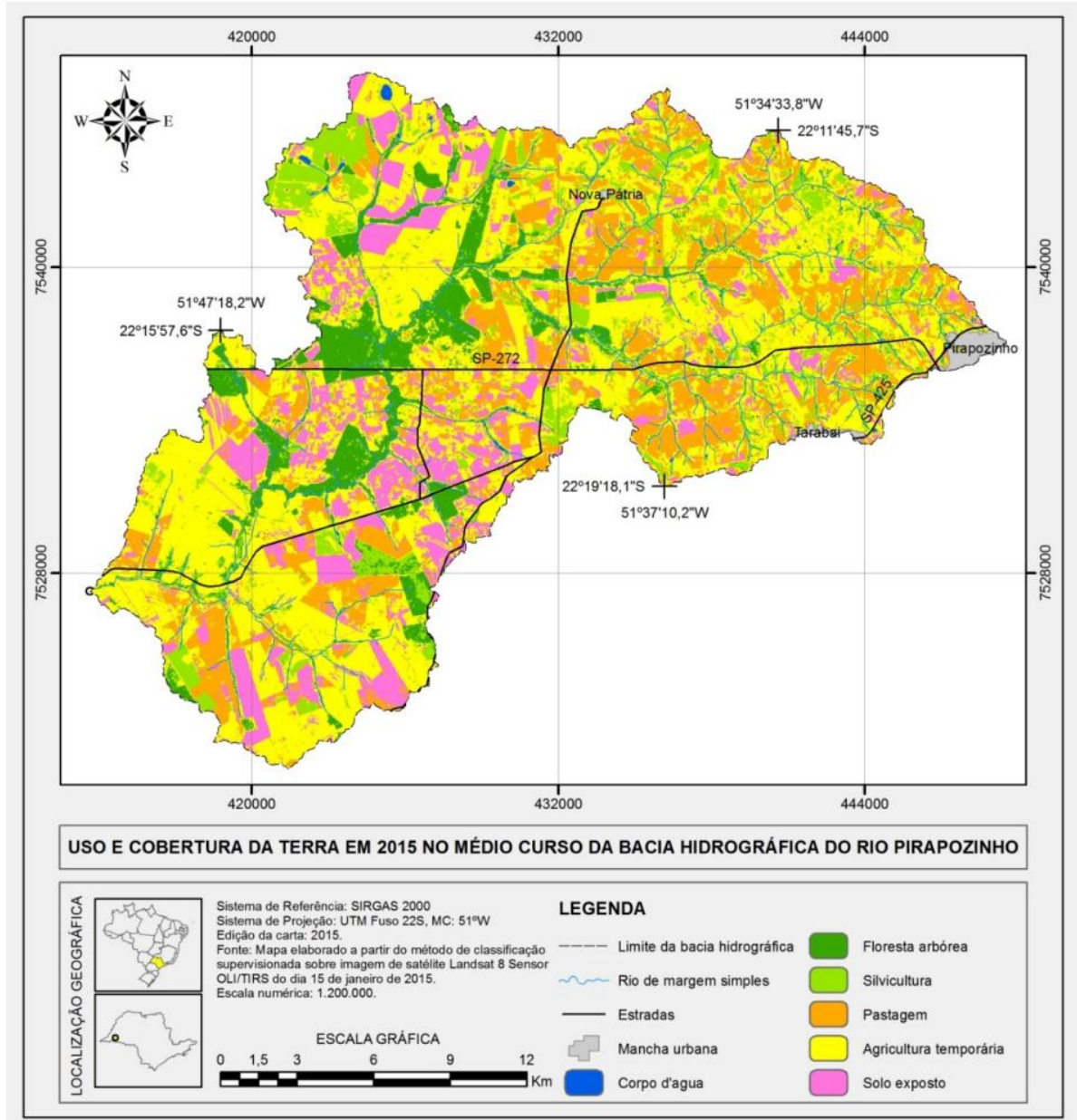

Figura 8. Uso e cobertura da terra em 2015 no médio curso da bacia do rio Pirapozinho. 
A Figura 9 aponta as fisionomias de vegetação presentes na bacia, bem como sua distribuição identificada no ano de 2013. A bacia possui como principal fisionomia Cerrado. Trechos isolados de Floresta Estacional Semidecidual (Mata Atlântica do Interior) são encontradas na bacia. Essa vegetação apresenta a perda parcial de folhagens (cerca de 50\%) durante os meses de estiagem e de menores temperaturas. Em locais próximos aos recursos hídricos é possível observar a presença de uma vegetação arbustiva, de características hidrófilas em regiões sujeitas ao hidromorfismo.

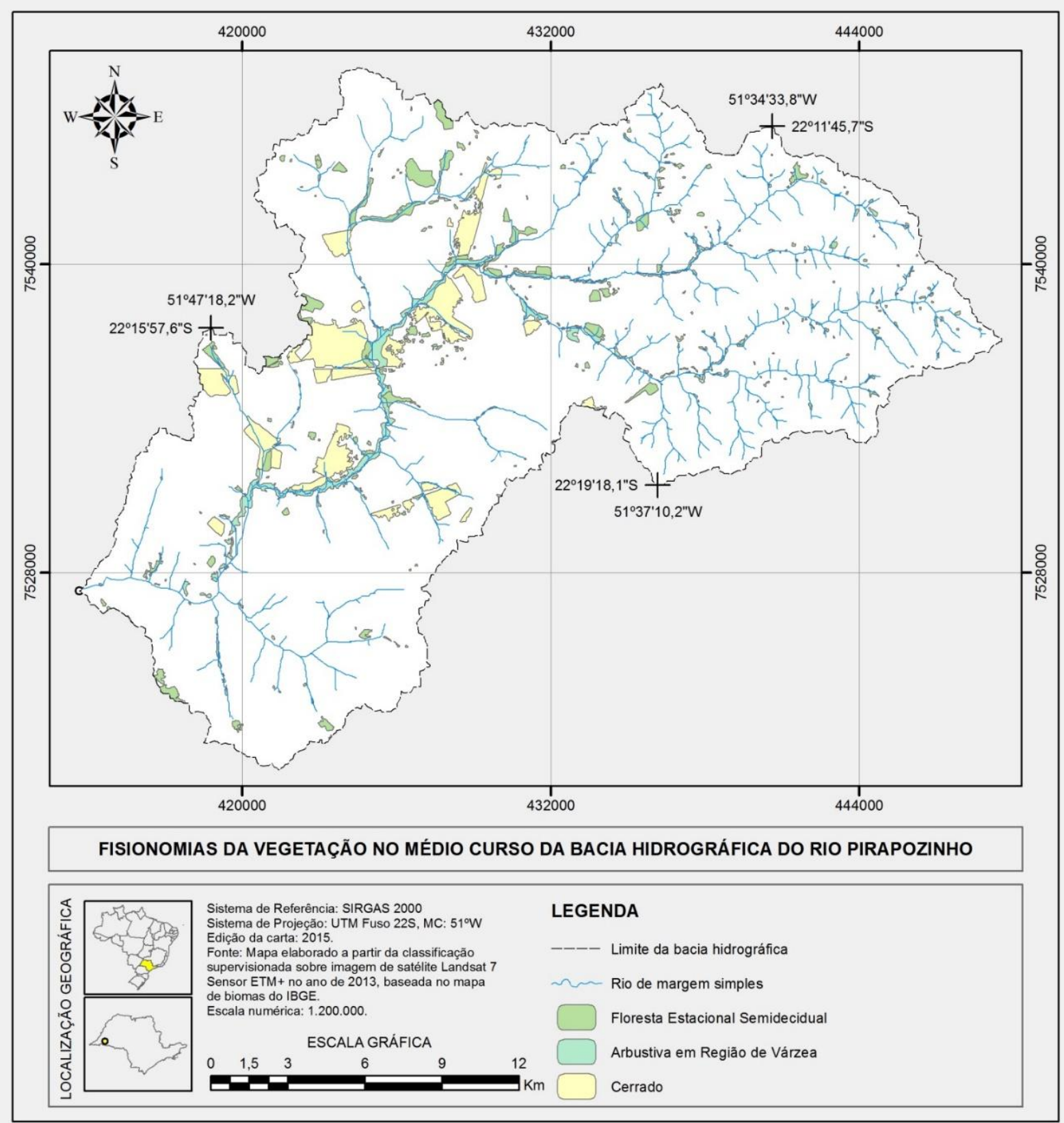

Figura 9. Fisionomias da vegetação no médio curso da bacia hidrográfica do Rio Pirapozinho 
A Figura 10 apresenta o mapa de suscetibilidade a erosão. A partir de correlações com os demais aspectos físicos analisados na área, pode-se compreender o porquê da suscetibilidade aos processos erosivos na bacia. Os trechos de maior declividade acabam por coincidirem com as regiões de maior suscetibilidade a processos erosivos, assim como as localidades mais planas são áreas com menor suscetibilidade. Coincide também a resistência do maciço rochoso que define a dimensão de processos de intemperismos. Todos esses fatores influenciam na formação dos solos, visto que quanto maior o intemperismo, maior será o desgaste das rochas favorecendo o desenvolvimento da pedogênese local.

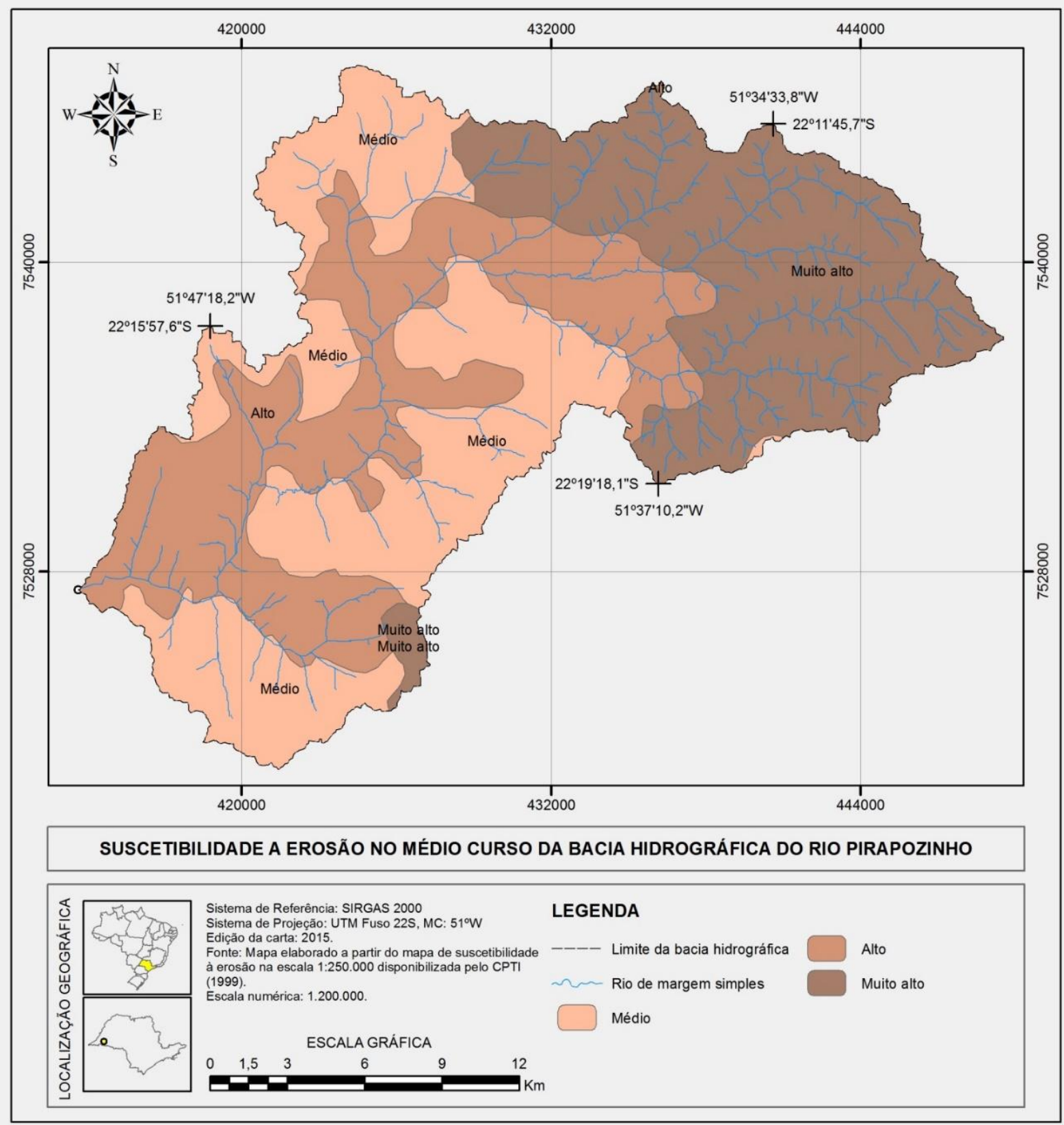

Figura 10. Suscetibilidade a erosão no médio curso da bacia hidrográfica do rio Pirapozinho 
A Figura 11 apresenta o mapa de drenagem do médio curso da bacia hidrográfica do rio Pirapozinho. Este produto auxilia na compreensão da distribuição dos recursos hídricos da bacia, bem como na identificação da dinâmica fluvial pertencente a esse contexto. Destaca-se a diferenciação da drenagem nas porções nordeste e central. ramificação da drenagem, conferindo o padrão dendrítico de drenagem. Na porção central identifica-se drenagens mais esparsas, com menor índice de ramificação. Correlaciona-se esse comportamento distinto com as características físicas levantadas nos mapas anteriores, tais como a morfologia do relevo, declividade e geologia. $\mathrm{Na}$ porção nordeste há uma maior

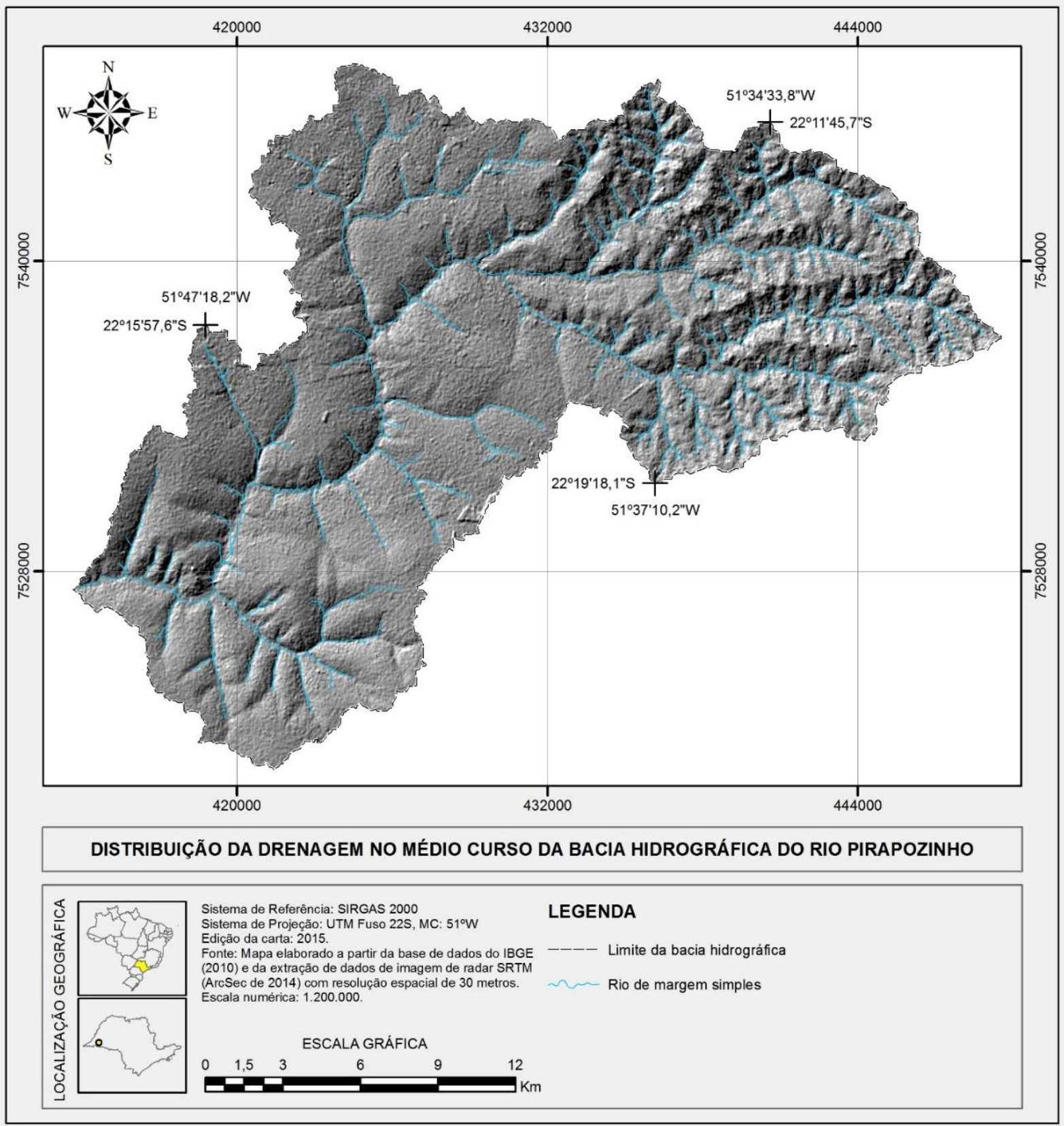

Figura 11. Distribuição da drenagem do médio curso da bacia hidrográfica do rio Pirapozinho 


\section{DISCUSSÃO}

Um total de 10 produtos cartográfico foram elaborados para compor o inventário físico-territorial do médio curso da bacia hidrográfica do rio Pirapozinho. As características levantadas por meio dos mapas temáticos proporcionaram compreender melhor a dinâmica da bacia estudada e possibilitou estabelecer relações entre os esses elementos.

Observou-se que a região estudada apresenta menor declividade em sua região central, coincidindo com a região da depressão de Presidente Bernardes. Além disso, possui declividade mais acentuada em sua porção nordeste. Fatores diferenciados na porção nordeste evidenciam a disparidade com o restante do contexto da bacia, onde é possível destacar: solos de caráter mais argiloso no seu horizonte $b$ textural; as características semelhantes entre as unidades geológicas $\mathrm{Ka}_{4}$ e $\mathrm{Ka}_{5}$ relacionadas com a intercalação de bancos silto-argilosos; as unidades morfológicas, que revelam a presença de colinas médias, mais dissecadas e com maiores índices de declividade; a relação com o uso e a cobertura da terra, apresentando regiões menos vegetadas; suscetibilidade a erosão ser muito alta e; a drenagem com caráter mais ramificado e padrão dendrítico.

\section{CONCLUSÕES}

Este trabalho apresentou a produção cartográfica necessária para compor o inventário físico-territorial do médio curso da bacia hidrográfica do rio Pirapozinho. Todas as questões do trabalho foram devidamente respondidas, uma vez que se tornou possível compreender quais elementos integram um inventário físico-territorial, bem como qual a característica físico-territorial da área que compreende o médio curso da bacia hidrográfica do rio Pirapozinho.

Conclui-se que cada característica física da região estudada possui sua parcela de colaboração no auxílio a compreensão de um todo, permitindo, em um momento posterior, integrar as informações obtidas ao planejamento ambiental da área de estudo. Conclui-se, também, que é necessário interpretar as características ambientais de forma sistêmica, buscando compreender as relações entre os diversos componentes naturais existentes, não descartando a interligação dos mesmos. Essa perspectiva integrada, com o suporte cartográfico, proporciona o gerenciamento mais adequado para a bacia hidrográfica trabalhada.

Recomenda-se que os mapas temáticos elaborados no decorrer do presente trabalho integrem o inventário físico-territorial do médio curso da bacia hidrográfica do rio Pirapozinho. Posteriormente, sugere-se que esses mapas 
sejam utilizados como subsídio à próxima etapa de planejamento ambiental, a qual corresponde ao diagnóstico da área de estudo.

\section{REFERÊNCIAS}

BOIN, M. N. Chuvas e erosões no Oeste Paulista: uma análise climatológica aplicada. 2000. 264f. Tese (Doutorado) - IGCE / UNESP, Rio Claro - SP.

COOPERATIVA DE SERVIÇOS E PESQUISAS TECNOLÓGICAS E INDUSTRIAIS. Relatório Zero da bacia hidrográfica do Pontal do Paranapanema. São Paulo: CPTI, 1999.

EMBRAPA. Oliveira, J. B. et al. Mapa Pedológico do Estado de São Paulo: legenda expandida. Campinas, Instituto agronômico; Rio de Janeiro: Embrapa Solos, 1999.

INSTITUTO DE PESQUISAS TECNOLÓGICAS DO ESTADO DE SÃO PAULO. Mapa Geomorfológico do Estado de São Paulo, 1:1.000.000. São Paulo, IPT. v. 2. 1981.

LEAL, A. C. Meio ambiente e urbanização na microbacia do Areia Branca - Campinas-SP. 1995. 155f. Dissertação (Mestrado) - Instituto de Geociências e Ciências Exatas, Universidade Estadual Paulista, Rio Claro SP.

LEAL, A. C. Planejamento ambiental de bacias hidrográficas como instrumento para 0 gerenciamento de recursos hídricos. Entrelugar, v. 3, n. 6, p. 65-84, 2012.

MOTA, S. Gestão ambiental de recursos

hídricos. Rio de Janeiro: ABES, 2008. 342p.

RODRIGUEZ, J.M.M. Planejamento ambiental como campo de ação da Geografia. In: CBG. Anais... v.1. AGB, 1994, Curitiba- PR. paisagens: uma visão geossistêmica da análise ambiental. Fortaleza: Editora da UFC. 2013. 222p.

SANTOS, R.F. Planejamento ambiental: teoria e prática. São Paulo: Oficina de Textos, 2004. 184p.

STEIN, D. P. Avaliação da degradação do meio físico - Bacia do rio Santo Anastácio, oeste paulista. 1999. 2 v. Tese (Doutorado em Geociências) - Instituto de Geociências e Ciências Exatas, Universidade Estadual Paulista, Rio Claro, 1999.

STEIN, D. P.; PONÇANO, W. L.; SAAD, A. R. Erosão na bacia do Rio Santo Anastácio, Oeste do Estado de São Paulo, Brasil. Revista Geociências, v. 22, n. 2, p. 143-162, 2003.

$\begin{array}{lll}\text { RODRIGUEZ, J.M.M.; SILVA, E.V.; } & \end{array}$ 